Research Article

\title{
Mechanical Properties Improvement Mechanism of Silica Fume-Modified Ultrafine Cement Used to Repair Pavement Microcracks
}

\author{
Xiaofei Wang $\mathbb{D}^{1},{ }^{1}$ Jiangbei Yao, ${ }^{2}$ Xinwei $\mathrm{Li}^{3}{ }^{3}$ Yinchuan Guo $\mathbb{D}^{4},{ }^{4}$ Aiqin Shen, \\ and HuaQiao $\mathrm{Pu}^{2}$ \\ ${ }^{1}$ Associate Professor, School of Civil Engineering and Transportation, South China University of Technology, \\ Guangzhou 510640, China \\ ${ }^{2}$ Master, School of Civil Engineering and Transportation, South China University of Technology, Guangzhou 510640, China \\ ${ }^{3}$ Senior Engineer, Guangzhou Expressway Company Limited, Guangzhou 510288, China \\ ${ }^{4}$ Associate Professor, School of Highway, Chang'an University, Xi'an 710064, China \\ ${ }^{5}$ Professor, School of Highway, Chang'an University, Xi'an 710064, China
}

Correspondence should be addressed to Xiaofei Wang; xiaofeiw@scut.edu.cn and Yinchuan Guo; silver007007@163.com

Received 5 July 2018; Revised 11 September 2018; Accepted 20 September 2018; Published 17 October 2018

Academic Editor: Francesco Ruffino

Copyright ( 2018 Xiaofei Wang et al. This is an open access article distributed under the Creative Commons Attribution License, which permits unrestricted use, distribution, and reproduction in any medium, provided the original work is properly cited.

\begin{abstract}
With heavy modern traffic and natural factors, cement concrete pavement cracks have become increasingly serious. However, most existing inorganic repair materials for cement concrete pavement cracks have low interfacial bonding strength. Ultrafine cement, silica fume (SF), and other admixtures, which are superfine and used to repair fine early cracks, are prepared as the mending material in our research. Compression strength, bending strength, and interfacial bonding strength are studied, and modification mechanisms are discovered by using a powder X-ray diffraction test, thermal analysis, and micromorphology observation. The result shows that mechanical strength of the stable period is improved with the right amount of mixing of SF, which leads to secondary pozzolanic reaction and makes the microstructure of the paste denser. Meanwhile, a large amount of Ca $(\mathrm{OH})_{2}$ and water in the interface area are consumed by the secondary pozzolanic reaction, which brings out good interfacial effects with no water film between the new paste and existing concrete. Our experiments show that the pastes with 3-5\% SF have better bending strength (15\% 17\% improvement) and compressive strength (7\% 9\% improvement). Interfacial bonding strength is also increased with a certain amount of SF. Tensile shear bonding strength has been improved more than 4 times when SF dosage is more than $3 \%$. Thus, we recommend a paste with $5 \%$ SF as the best mixture to be used to repair cracks.
\end{abstract}

\section{Introduction and Literature Review}

Due to its high strength, good stability, excellent durability, strong water resistance, and availability of cement, cement concrete pavement is widely used throughout the world [1]. However, under the influence of modern traffic and natural factors, damages to the pavement surface have become increasingly serious. Repair techniques and maintenance materials of pavement cracks are thus increasingly needed. In recent years, much research on pavement crack repair materials has been performed. Many research institutions and scholars in various countries are working diligently to find and develop new materials and new processes to solve cracking problems, such as the Concrete Association of the United States, Cement and Concrete in the United Kingdom Association, European Concrete Association, and Russian Academy of Concrete and Reinforced Concrete [2-4].

In 1992, Duan [5] introduced the properties and applications of latex-modified cement concrete, which plays an effective role in solving problems such as water seepage, water leakage, salt infiltration, chemical corrosion, brittle fracture, and low-temperature freezing. In 1993, $\mathrm{Li}$ and $\mathrm{Wu}$ [6] developed a CNL hardening accelerating admixture for concrete and $\mathrm{ZV}$ early strength interface treatment agent and conducted 
research on superfast strong concrete for rapid repair of pavement. Using a superplasticizer in SF-modified ordinary concrete, Xu and Xiao [7] suggested a new concrete mending material with high early strength, enhanced wear resistance, high bonding strength, and low price. In 1998, Ruan et al. [8] successfully developed an NC polymer concrete rapid repair agent and achieved good application effect in practical engineering applications. In 2003, Guan [9] repaired damaged cement concrete pavement with an $\mathrm{F}$ repair material.

For the past decades, the organic mixture (such as epoxy resin, polyurethane, and asphalt materials) was widely used to maintain and repair early-stage cement concrete pavement deformations, especially cracks. For example, a macromolecule polymer resin was used as a main raw material according to engineering conditions, with a certain amount of a curing agent, a filler, a diluent, a toughening agent, and an accelerator. The mixture turned out to be strong in adhesion, have good groutability, and have easy polymerization and hardening. The polymer mixture has a series of advantages such as impermeability, moisture resistance, and corrosion resistance. So, it was often applied to the reinforcement of concrete structure, cracks repair, impermeability, and plugging [2]. Epoxy grouting materials have low viscosity, good infiltration, good filling role for wide and deep cracks, high adhesion to the existing concrete, improved overall stiffness of the test piece, and improved mechanical strength [4]. For these reasons, geopolymers are increasingly popular as crack repair materials all over the world. However, factors that affect the performance of geopolymer materials are various $[10,11]$, such as water-cement ratio, alkali activator, water glass modulus, and maintenance method. Tchakoute et al. studied the effect of $\mathrm{Al}_{2} \mathrm{O}_{3} / \mathrm{Na}_{2} \mathrm{O}$ molar ratio on the setting time, linear shrinkage, and compressive strength of geopolymers mixture [12]. Wang et al. studied the mechanical properties of geopolymers mixture when fly ash was replaced by mineral powder, whose results showed that the mechanical properties of the synthesized geopolymers are significantly improved [13]. Vance et al. studied the effect of different alkali activators and concentration on the rheological properties of fly ashbased polymer mixtures [14]. The study of the main synthetic materials in the world's polymer research had changed from traditional kaolin to fly ash [13-16]. Yang et al.'s results showed that the compressive performance of the synthetic alkali activator material has excellent pressure resistance when the water-cement ratio was less than 0.3 [17].

However, the disadvantage of the polymer mixture is that the coefficient of thermal expansion is quite different from that of concrete and cement products. The shrinkage of the resin after curing is quite large, the requirements for the pavement surface are relatively high (clean and dry), and the monomers or polymers are liable to cause environmental pollution [3]. Furthermore, although these materials can be used to reinforce, bond, and seal concrete, there are still obviously defects such as poor compatibility with pavement cement concrete, short service life, high construction costs, and unfavorable environmental protection [18]. In 2011, Zhou et al. [19] studied a kind of magnesium phosphate cement (MPC) for CCP cracks and discussed the main factors affecting the final setting time and compressive strength of magnesium phosphate cement. In 2014, Li et al. [20] carried out research on slag-based CCP repair materials. Deng investigated the properties of the fly ash-based polymers for the rapid repair of cement concrete pavement materials [2]. It can be found that the pavement repair materials gradually transfer from organic mixture to inorganic mixture based on cement. The research goal is more concerned about environmental protection and energy-saving in recent years.

Due to the fineness of the UFC and cement-based material, it can be poured into fine microcracks and has good compatibility with the cement concrete. Thus, we selected UFC as the basic material. However, due to the fine particles, the UFC rapidly hydrates with water, which results in a rapid increase in viscosity. Thus, it is not conducive to construction operations. SF can retard hydrating and slow down the condensation hardening to improve the fluidity, and with SF mixed in the UFC, secondary pozzolanic reaction will be performed. Furthermore, SF plays a role in particle filling and enhancing interfacial adhesion, mechanical properties, and durability. Therefore, SF was selected as a modifier in order to develop excellent performance as CCP cracks the material. Based on operational viscosity, setting time, and groutability, the initial proportioning mixture was designed to be evaluated as crack repair materials, including compression strength, bending strength, and interfacial bonding strength. Furthermore, the modification mechanism was explored with powder X-ray diffraction, thermal analysis test, and microstructure observation.

\section{Experiment}

2.1. Materials. U-type Portland UFC was determined to be used in the experiment. The UFC is an inorganic grouting material composed of fine Portland cement particles, 50\% of which have a particle size of $4 \mu \mathrm{m}$ to $6 \mu \mathrm{m}$, a maximum particle size of no more than $20 \mu \mathrm{m}$, and a specific surface area of $850 \mathrm{~m}^{2} / \mathrm{kg}$ (Table 1 ).

SF with high silicon and stable performance was selected in our research, and specific surface area of selected SF is $3000-4000 \mathrm{~cm}^{2} / \mathrm{g}$. Other performance indicators are shown in Table 2. To compensate for the material's fluidity and shrinkage during hardening, an expansion agent and a water-reducing agent were added into the mixture paste.

2.2. Mixture Proportioning. In this study, the initial design of the mixture proportioning was based on the following 3 indicators: viscosity, setting time, and groutability. The relationship between $\mathrm{W} / \mathrm{C}$ and viscosity, setting time, and groutability was established, and the proportioning satisfactory for construction was selected accordingly. Then with setting time as a contrast indicator, mixtures with better working performance in these proportions were determined as shown in Table 3. With silica fume added into the paste, we found more water was needed to satisfy construction needs.

\subsection{Experiments}

2.3.1. Mechanical Properties. $40 \mathrm{~mm} \times 40 \mathrm{~mm} \times 160 \mathrm{~mm}$ paste specimens were prepared and cured under standard 
TABLE 1: Performance indicators of UFC.

\begin{tabular}{|c|c|c|c|c|c|c|}
\hline Granularity $(\mu \mathrm{m})$ & Cumulative (\%) & Frequency (\%) & Granularity $(\mu \mathrm{m})$ & Cumulative (\%) & Frequency (\%) & \\
\hline 100.0 & 0.0 & 0.0 & 7.0 & 23.6 & 16.6 & $\begin{array}{c}\text { Volume concentration } \\
=2.42 E-03 \% \\
N=1.36\end{array}$ \\
\hline 80.0 & 0.0 & 0.0 & 5.0 & 40.2 & 16.9 & $\bar{X}=5.35$ \\
\hline 63.0 & 0.0 & 0.0 & 3.5 & 57.1 & 6.4 & $D(3,2)=2.05 \mu \mathrm{m}$ \\
\hline 50.0 & 0.0 & 0.0 & 3.0 & 63.5 & 6.7 & $D(\mathrm{v}, 97 \%)=0.41 \mu \mathrm{m}$ \\
\hline 40.0 & 0.0 & 0.0 & 2.5 & 70.2 & 6.8 & $D(\mathrm{v}, 95 \%)=0.61 \mu \mathrm{m}$ \\
\hline 28.0 & 0.0 & 0.2 & 2.0 & 77.0 & 6.8 & $D(\mathrm{v}, 94 \%)=0.70 \mu \mathrm{m}$ \\
\hline 20.0 & 0.2 & 2.2 & 1.5 & 83.8 & 6.5 & $D(\mathrm{v}, 5 \%)=11.95 \mu \mathrm{m}$ \\
\hline 14.0 & 2.4 & 7.1 & 1.0 & 90.4 & 5.8 & $D(\mathrm{v}, 3 \%)=13.41 \mu \mathrm{m}$ \\
\hline 10.0 & 9.5 & 14.1 & 0.5 & 96.1 & & \\
\hline \multicolumn{3}{|c|}{$D(\mathrm{v}, 10 \%)=9.85 \mu \mathrm{m}$} & \multicolumn{3}{|c|}{$D(\mathrm{v}, 40 \%)=5.02 \mu \mathrm{m}$} & $D(\mathrm{v}, 70 \%)=2.51 \mu \mathrm{m}$ \\
\hline \multicolumn{3}{|c|}{$D(\mathrm{v}, 20 \%)=7.58 \mu \mathrm{m}$} & \multicolumn{3}{|c|}{$D(\mathrm{v}, 50 \%)=4.09 \mu \mathrm{m}$} & $D(\mathrm{v}, 80 \%)=1.78 \mu \mathrm{m}$ \\
\hline \multicolumn{3}{|c|}{$D(\mathrm{v}, 30 \%)=6.13 \mu \mathrm{m}$} & \multicolumn{3}{|c|}{$D(\mathrm{v}, 60 \%)=3.27 \mu \mathrm{m}$} & $D(\mathrm{v}, 90 \%)=1.03 \mu \mathrm{m}$ \\
\hline
\end{tabular}

Note: $N$ : shape factor; $\bar{X}$ : parameter related with the instrument; $D(3,2)=2.05$ : average particle size is $2.05 \mu \mathrm{m}$ at area percentage; $D(\mathrm{v}, \%)$ : particle size at volume cumulative percentage.

TABle 2: Performance indicators of SF.

\begin{tabular}{lcccccc}
\hline Water $(\%)$ & $\mathrm{S}_{\mathrm{i}} \mathrm{O}_{2}(\%)$ & $\mathrm{Fe}_{2} \mathrm{O}_{3}(\%)$ & Loss on ignition $(\%)$ & $\mathrm{pH}$ & $D 50(\mu \mathrm{m})$ & Specific surface area $\left(\mathrm{cm}^{2} / \mathrm{g}\right)$ \\
\hline 0.1 & 99.4 & 0.03 & 0.15 & 7 & $8-10$ & $3000-4000$ \\
\hline
\end{tabular}

TABLE 3: Mixture proportioning of SF-modified UFC.

\begin{tabular}{lccccc}
\hline Sample & SF (\%) & W/C & W/B & $\begin{array}{c}\text { Expansion } \\
\text { agent }\end{array}$ & $\begin{array}{c}\text { Water-reducing } \\
\text { agent }\end{array}$ \\
\hline GC0 & 0 & 0.5 & 0.5 & 8 & 0.8 \\
GC1 & 3 & 0.55 & 0.534 & 8 & 0.8 \\
GC2 & 5 & 0.55 & 0.524 & 8 & 0.8 \\
GC3 & 7 & 0.55 & 0.515 & 8 & 0.8 \\
GC4 & 9 & 0.55 & 0.505 & 8 & 0.8 \\
GC5 & 11 & 0.55 & 0.495 & 8 & 0.8 \\
\hline
\end{tabular}

conditions for 3 days. Then, they were cured under natural conditions until the specified curing age. We tested mechanical strength for an age of 1 day, 3 days, 7 days, and 28 days. XRD DTA/TG and SEM tests were performed on the hydration products at 28 days of curing age. After the test piece was ready, it was placed into the instrument for testing according to Test Regulations of Cement and Concrete for Highway Engineering [21]. The KZJ6000-2 cement electric bending testing instrument was used to test the bending strength of the specimens, and the MYL-30-type pressuretesting machine was used to test the compressive strength of the specimens.

2.3.2. Tensile Shear Bonding Strength. The bonding strength test method was a self-designed method that approximately simulates the stress pattern of CCP subjected to tensile shear. This method was also introduced in our previous paper [22]. The SF-modified UFC paste was poured onto the existing concrete and cured to the specified age. Bonding strength between SF-modified UFC and existing concrete was tested by tensile stretching and shearing (Figure 1). $F$ is the tensile force. $\theta$ is $80-85^{\circ}$. We tested mechanical strength for a curing age of 28 days.

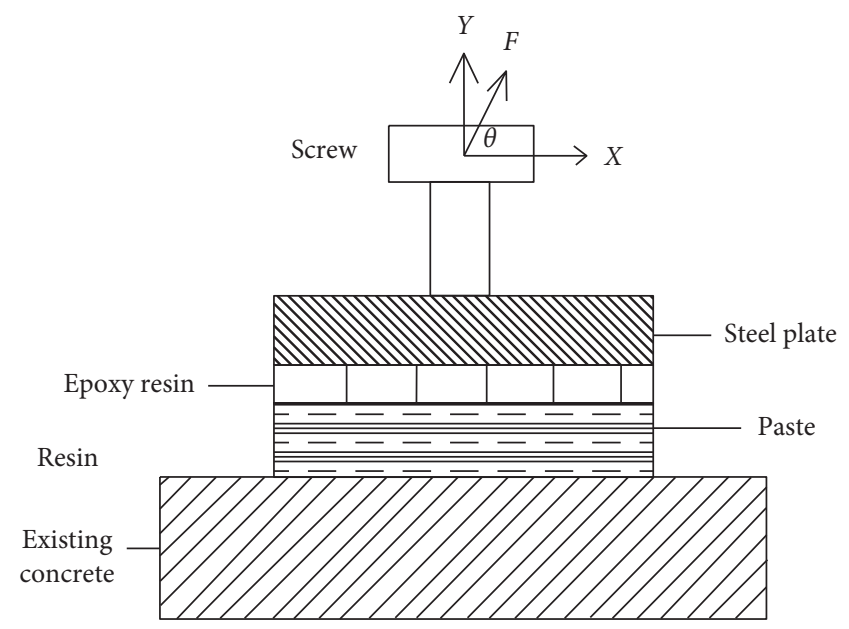

FIgURE 1: Test model for tensile shear bonding strength.

2.3.3. Bending Tensile Bonding Strength. The bending tensile bonding strength test of SF-modified UFC paste is shown in Figure 2. Firstly, cement gel sand specimens have been prepared and cured for more than 28 days under standard conditions. Then, the specimens were broken carefully into halves with an approximately perpendicular surface as shown in Figure 2. Acetone was used to clean the broken surface. One half was put into a mold, and the SF-modified UCF material was poured into the other half of the mold. After curing for 1 day under natural conditions, the mold was removed and put into standard room for 28 days of curing. Then, the specimens were tested for their bending tensile bonding strength. The strength was tested on an electric bending testing machine. This method was also introduced in our previous paper [22]. 


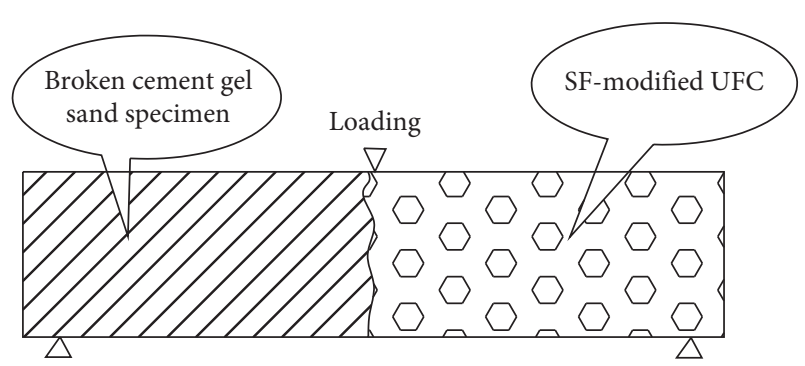

Figure 2: Test model for bending tensile bonding strength.

\subsubsection{Powder X-Ray Diffraction and Thermal Analysis.} The X-ray diffraction (XRD) test was conducted on a D/Max 2550V X-ray diffractometer at the National Key Laboratory of Concrete of Tongji University. The characteristic diffraction peaks of $\mathrm{Ca}(\mathrm{OH})_{2}, \mathrm{Aft}, \beta-\mathrm{C} 2 \mathrm{~S}$, and $\mathrm{CaCO}_{3}$ were observed and compared for different amounts of SF. Thus, the modification mechanism could be revealed.

Thermal analysis includes differential thermal analysis (DTA) and thermogravimetric analysis (TG). The experiments were performed at the Shanghai State Key Laboratory of Metal Matrix Composites at Shanghai Jiao Tong University. The thermal analyzer (TGA-7) and the high-temperature differential thermal analyzer (DTA1600) were used. Main performance indicators of TGA-7 thermal analysis are maximum weighing, $1300 \mathrm{mg}$; weighing sensitivity, $0.1 \mu \mathrm{g}$; range of temperatures, room temperature $1000^{\circ} \mathrm{C}$; temperature accuracy, $\pm 2^{\circ} \mathrm{C}$; and weighing accuracy, $10 \mathrm{ppm}$. Main performance indicators of DTA1600 are range of temperatures: room temperature $1600^{\circ} \mathrm{C}$, and sensitivity: $0.001^{\circ} \mathrm{C}$.

Specimens should be prepared as follows:

(a) $40 \mathrm{~mm} \times 40 \mathrm{~mm} \times 160 \mathrm{~mm}$ specimens have been prepared and cured for 3 days under standard conditions. Then, these specimens were cured under natural conditions for 28 days.

(b) Remove the surface layer that was carbonized.

(c) Crush and grind the left central part. Sieve by a 350mesh $(44 \mu \mathrm{m})$ sieve to obtain a crystal grain size of 10 to $40 \mu \mathrm{m}$.

(d) Immerse in absolute alcohol to stop hydration, filter, and bake at $60^{\circ} \mathrm{C}$ for 16 hours to constant weight.

(e) Place in a sealed dry vial for X-ray diffraction and thermal analysis.

2.3.5. Micromorphology. The S-2360N scanning electron microscope was used to observe the SEM images of the hydration products and the bonding interface of the SFmodified UFC. Thin and flat slices were required for scanning observation. Thus, the samples were taken from the center of the specimens and soaked in anhydrous alcohol to remove the moisture and stop the hydration. Then, the samples were baked at $60^{\circ} \mathrm{C}$ for 16 hours to constant weight and placed in a sealed dry vial for scanning observation. Before the observation, a layer of about $10 \mathrm{~nm}$ metal conductive film was sputtered on the surface of the samples.

\section{Results and Discussion}

3.1. Mechanical Strength. After the CCP crack was repaired, the SF-modified UCF bears the load along with the existing pavement. The mechanical strength is very important. In this paper, compressive strength and bending strength of SFmodified UCF at 1 day, 3 days, 7 days, and 28 days of curing age were studied. Strength development bar charts are shown in Table 4 and Figures 3 and 4. According to Highway Cement Concrete Pavement Design Specification [23], 28 days' bending strength and compressive strength of regular cement concrete pavement should be $5.0 \mathrm{MPa}$ and $42.0 \mathrm{MPa}$ separately which are very close to those of our repair materials.

The strength formation process of a cement paste can be explained in 3 stages. The first is the induction period lasting about 4 hours, generating a certain amount of ettringite (Aft) and $\mathrm{Ca}(\mathrm{OH})_{2}$ crystals. Then, the acceleration period and the deceleration period, which last for 4 to 8 hours and 12 to 24 hours, during which the strength gradually forms. The last period is the stabilization period, in which the intensity continues to increase with time.

Figures 3-6 show the following:

(1) At an age of 1 day, mechanical strength did not change significantly with the addition of SF, and the compressive strength tended to decrease. This may be because the addition of SF delayed the hydration induction period, acceleration period, and deceleration period so that the compressive strength of 1 day had a decreasing trend.

(2) At 3 days and 7 days, there were different degrees of improvement in compressive and bending strengths. SF normally does not react with water itself. But it can have the secondary pozzolanic reaction inspired by the cement hydration product $\mathrm{Ca}(\mathrm{OH})_{2}$ and some other compounds. Whether low $\mathrm{Ca} / \mathrm{Si} \mathrm{CSH}$ gel and spatial crystal structure of needle columnar calcium vanadium can be synthesized is related to the amount of SF added.

(3) At 28 days, the amount of SF added made the compressive strength and bending strength increase obviously. While with the increase of SF proportion, the trend of increase in bending strength decreased, but the compressive strength tended to decrease.

The above test results showed that the addition of SF delayed the hydration induction period, acceleration period, and deceleration period so that the compressive strength of 1 day had a decreasing trend. The appropriate amount of SF can improve strength of stabilization.

To prove our judgement, XRD and DTA/TG tests were performed on the hydration products of 10 samples for 28 days of curing age. The results showed that $\mathrm{Ca}(\mathrm{OH})_{2}$ in the hydrated products of GC1 to GC5 was lower than that in the hydrated products of GC0. Main characteristic peak height of $\mathrm{Ca}(\mathrm{OH})_{2}(d=2.63)$ was in the order of GC5 $<\mathrm{GC} 4<\mathrm{GC} 3$ $<$ GC2 < GC1 < GC0 (Table 5 and Figures 5 and 6). The content of calcium aluminate hydrate and the gel after modification by SF has been improved to varying degrees. The content of hydrated calcium aluminate and the gel in the 
TABLE 4: Strength of SF-modified UFC (MPa).

\begin{tabular}{lcccccccc}
\hline \multirow{2}{*}{ Category } & \multicolumn{2}{c}{1 day } & \multicolumn{2}{c}{3 days } & \multicolumn{2}{c}{7 days } & \multicolumn{2}{c}{28 days } \\
& Bending & Compressive & Bending & Compressive & Bending & Compressive & Bending & Compressive \\
\hline GC0 & 4.18 & 20.78 & 4.45 & 22.69 & 4.50 & 23.85 & 6.95 & 41.67 \\
GC1 & 4.83 & 17.14 & 4.90 & 30.73 & 6.47 & 38.65 & 8.03 \\
GC2 & 4.80 & 16.67 & 4.85 & 31.41 & 6.30 & 36.87 & 8.13 & 45.31 \\
GC3 & 5.23 & 18.33 & 5.37 & 29.48 & 6.07 & 37.08 & 7.72 & 36.88 \\
GC4 & 4.40 & 20.00 & 6.17 & 29.84 & 5.73 & 31.41 & 7.48 & 41.61 \\
GC5 & 5.13 & 19.01 & 5.73 & 29.06 & 6.63 & 35.36 & 7.63 & 40.68 \\
\hline
\end{tabular}

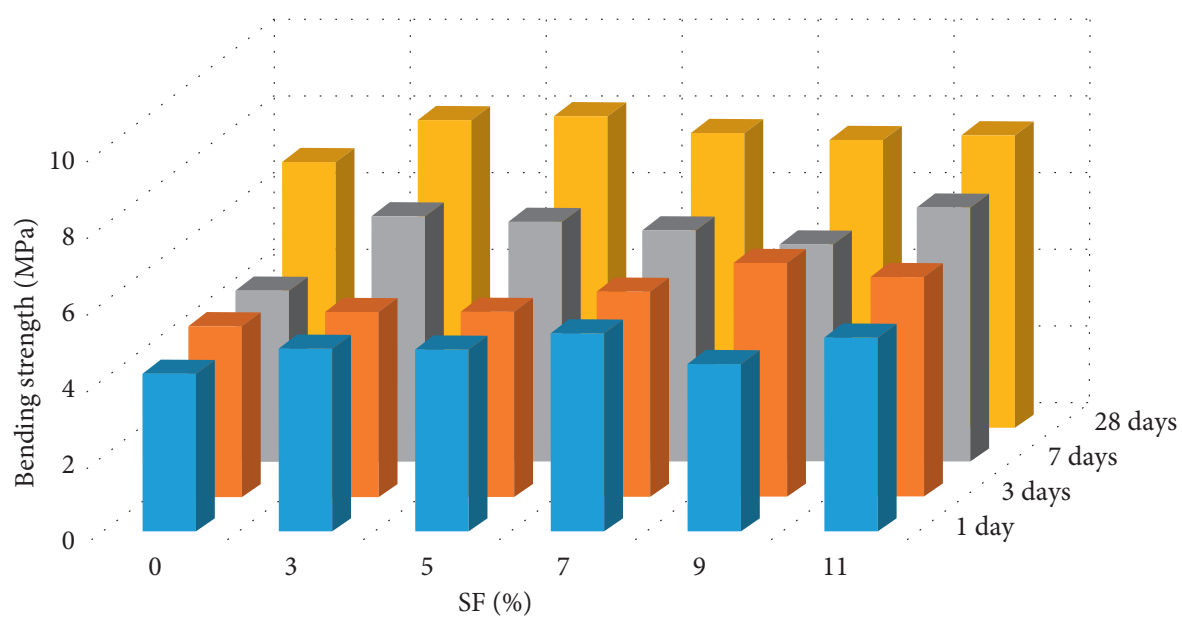

FIGURE 3: Bending strength of SF-modified UFC.

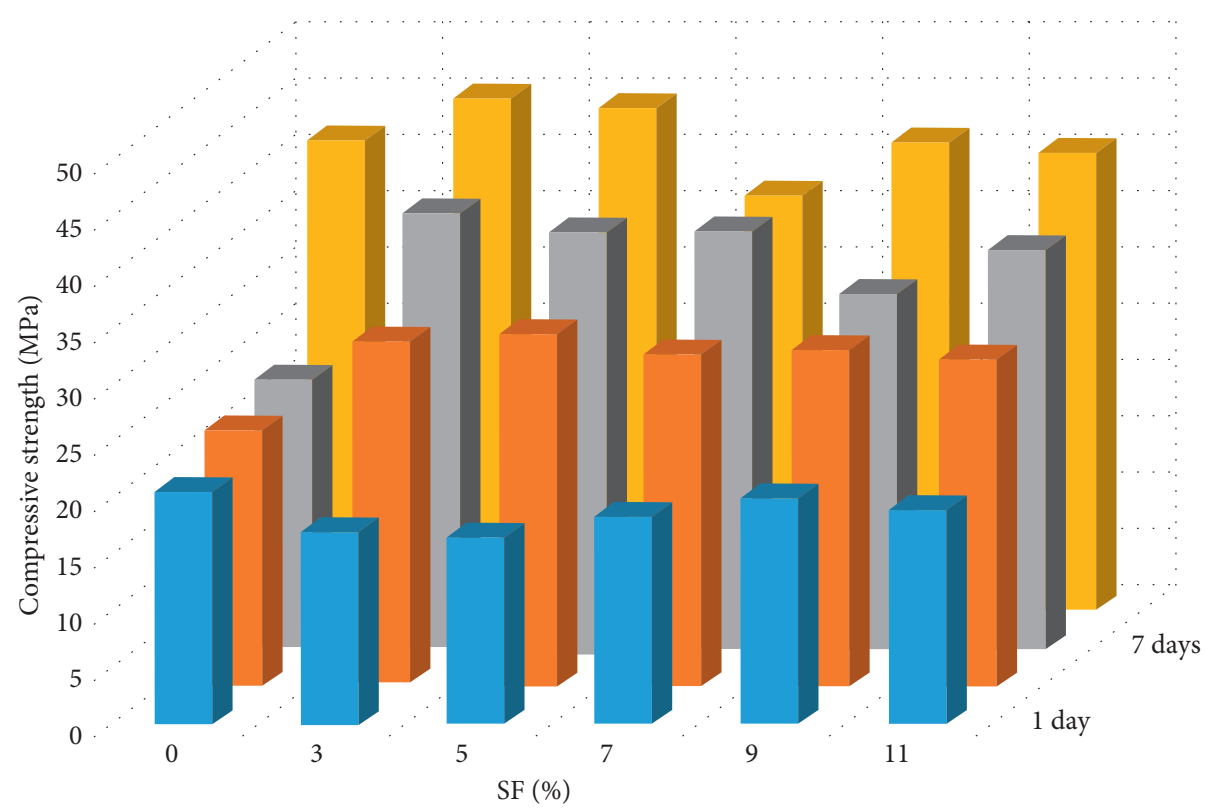

FIGURE 4: Compressive strength of SF-modified UFC.

samples was GC0 < GC1 < GC2 < GC3 < GC4 < GC5, as shown in Figures 7-9. From the view of the combined water content, the chemically bound water of the SF-modified materials increased with the increase of the SF content, indicating that the SF improved the hydration process of the UFC by transforming moisture into more chemically bound water.
Cement hydration reaction can produce pores up to $10 \mu \mathrm{m}$ and as small as $0.005 \mu \mathrm{m}$. Silica fume has volcanic ash activity. Part of the silica fume produced a good secondary pozzolanic reaction with $\mathrm{Ca}(\mathrm{OH})_{2}$ which is produced by UFC hydration reaction. Silica fume and secondary reaction product can fill the cement stone pore, especially big ones. Then, big pores are reduced and size distribution of the 
TABLE 5: 28-day diffraction peaks (cps) of SF-modified UCF.

\begin{tabular}{|c|c|c|c|c|c|c|c|c|c|}
\hline \multirow{2}{*}{ Specimens } & \multicolumn{2}{|c|}{$\mathrm{Ca}(\mathrm{OH})_{2}$} & \multirow{2}{*}{$\begin{array}{c}\text { Aft } \\
D=9.83\end{array}$} & \multirow{2}{*}{$\begin{array}{c}\beta-\mathrm{C} 2 \mathrm{~S} \\
D=2.85\end{array}$} & \multirow{2}{*}{$\begin{array}{c}\mathrm{CaCO}_{3} \\
D=3.04\end{array}$} & \multicolumn{2}{|c|}{$\mathrm{CaAl}_{2} \mathrm{Si}_{2} \mathrm{O}_{8} \mathrm{nH}_{2} \mathrm{O}$} & \multicolumn{2}{|c|}{$\mathrm{Ca}_{8} \mathrm{Al}_{4} \mathrm{Ol}_{4} \mathrm{CO}_{2} \mathrm{n}_{4} \mathrm{H}_{2} \mathrm{O}$} \\
\hline & $d=2.63$ & $d=4.92$ & & & & $d=3.34$ & $d=4.27$ & $d=8.20$ & $d=4.10$ \\
\hline GC0 & 612.33 & 666.33 & 136.00 & 138.33 & 166.68 & 388.33 & 56.67 & 135.00 & 78.33 \\
\hline GC1 & 586.68 & 531.68 & 143.33 & 133.33 & 156.68 & 571.67 & 91.67 & 123.33 & 91.67 \\
\hline GC2 & 558.83 & 526.68 & 145.00 & 151.68 & 146.68 & 443.33 & 91.67 & 116.67 & 86.67 \\
\hline GC3 & 550.00 & 556.68 & 136.00 & 151.68 & 143.68 & 648.33 & 88.33 & 125.00 & 76.67 \\
\hline GC4 & 543.33 & 496.68 & 136.68 & 146.68 & 148.33 & 220.00 & 65.00 & 116.67 & 63.33 \\
\hline GC5 & 538.33 & 508.36 & 136.65 & 143.33 & 136.68 & 316.67 & 76.67 & 106.67 & 75.00 \\
\hline
\end{tabular}

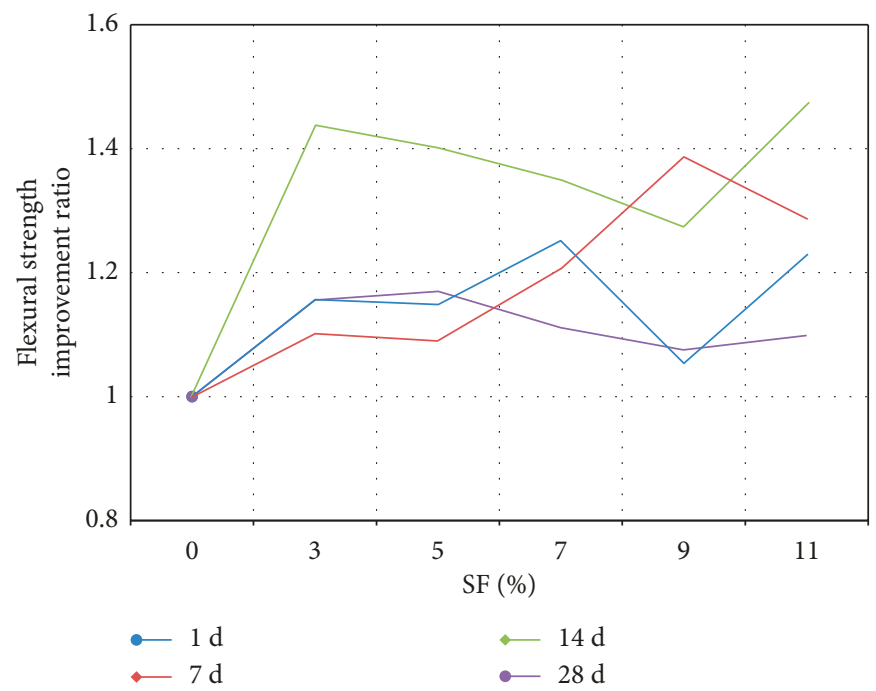

FIGURE 5: Flexural strength improvement ratio.

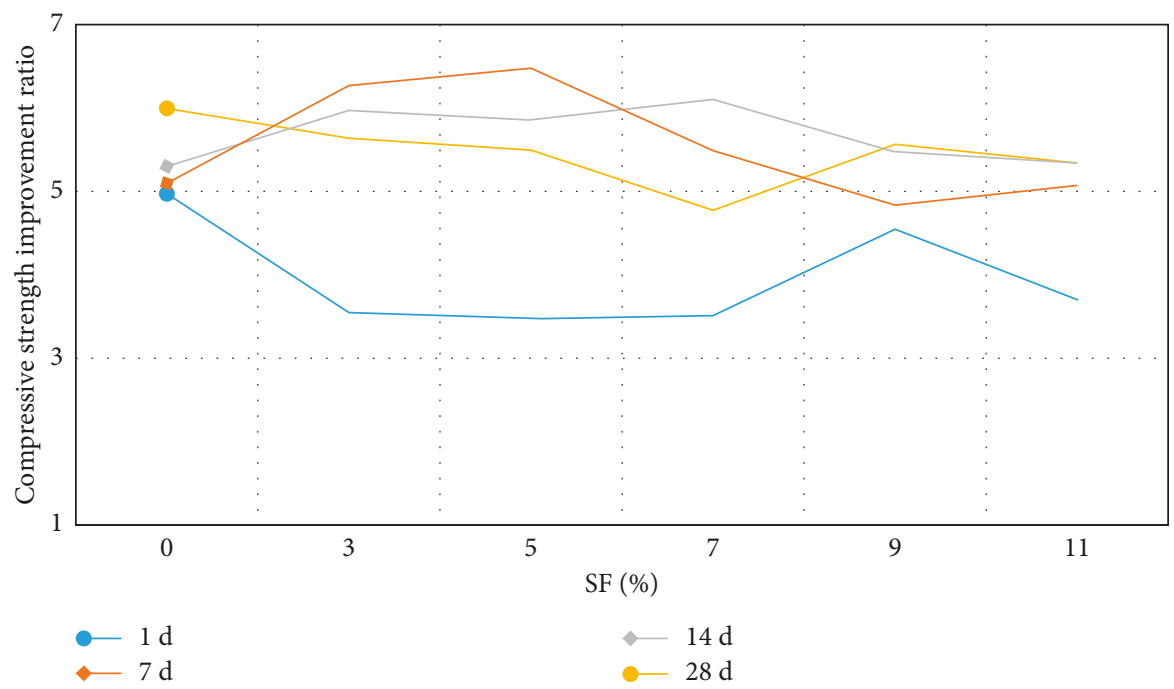

FIgURE 6: Compressive strength improvement ratio.

cement stone is optimized. Thus, the mechanical strength is improved, as shown in Figure 10. When SF was too much, there were relatively few activators and some of the SF remained. Thus, the secondary reaction could not completely proceed, and there were too many fine particles inside the cement paste, the adhesive slurry was lacking, and the repair material became loose. The mechanical properties of the specimens also deteriorated as shown in Figure 11.

3.2. Bonding Strength. For CCP crack repair materials, the most important property should be the interface bonding 


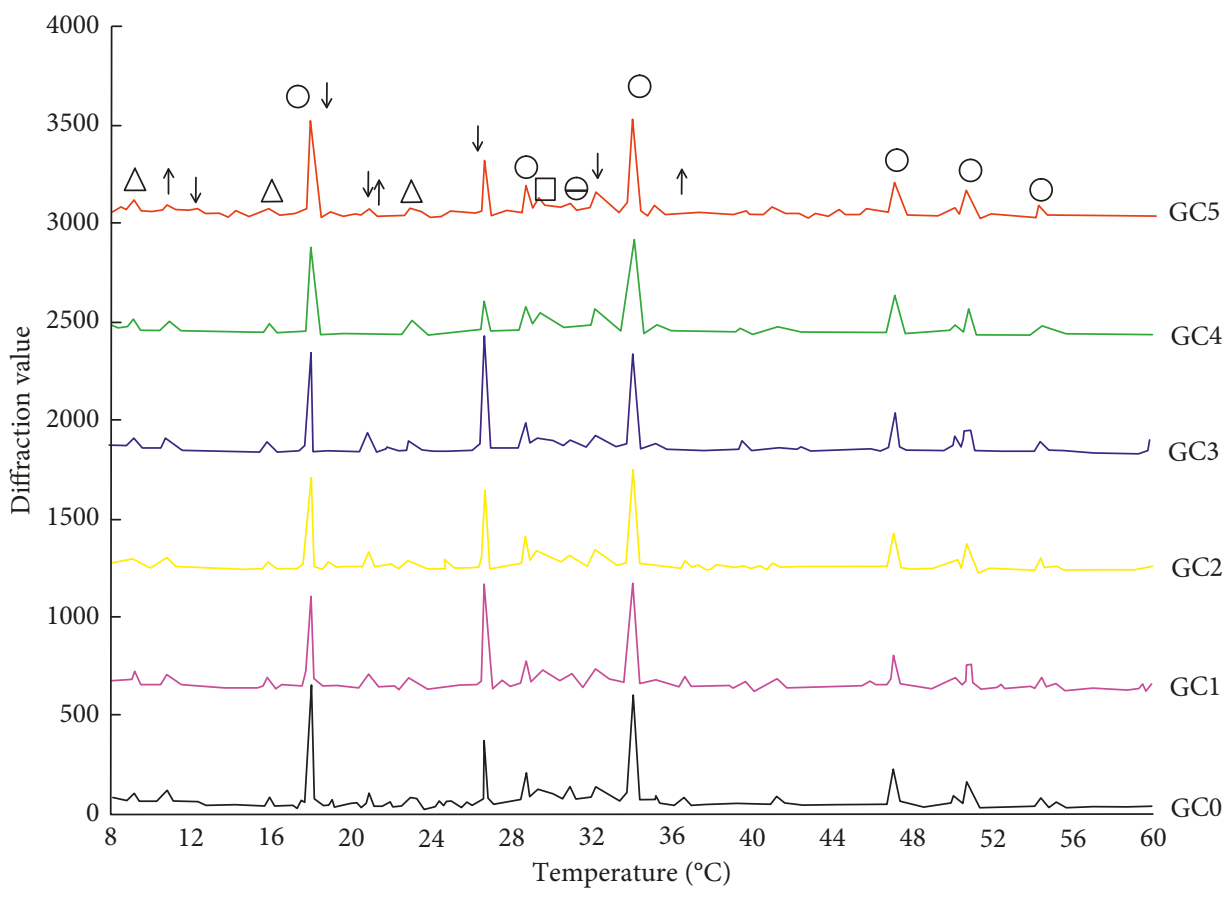

FIGURE 7: XRD of different mixture proportioning of SF-modified UFC.

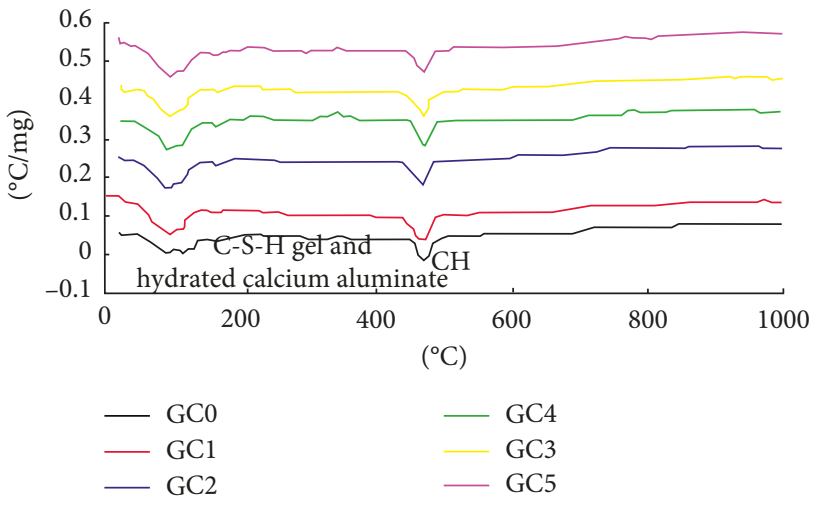

Figure 8: DTA of different mixture proportioning of SF-modified UFC.

(\%)

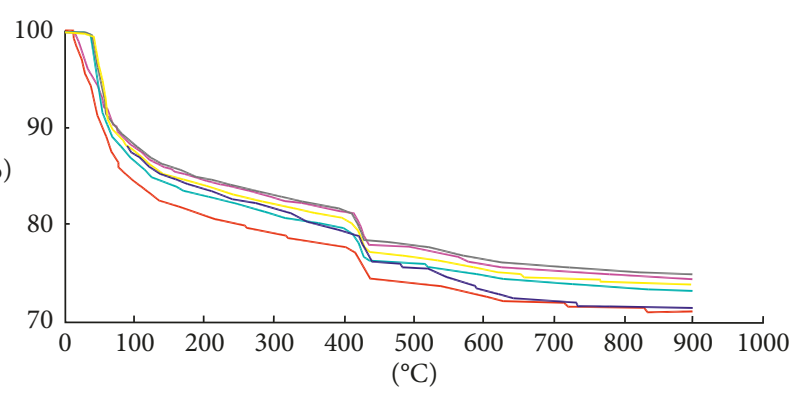

$$
\begin{array}{ll}
\text { GC0 } & - \text { GC3 } \\
- \text { GC1 } & - \text { GC4 }
\end{array}
$$

FIGURE 9: TG of different mixture proportioning of SF-modified UFC.

strength which is related to the occurrence of secondary damage to the original interface. The interface of cracks in concrete pavement after repair may suffer from shear,

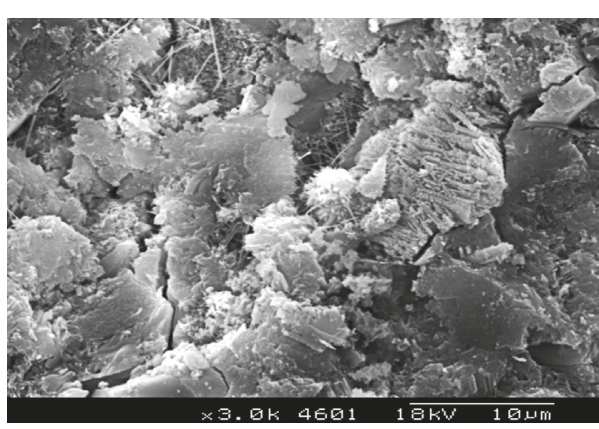

Figure 10: Microstructure of GC3 (proper amount of SF, at 28 days).

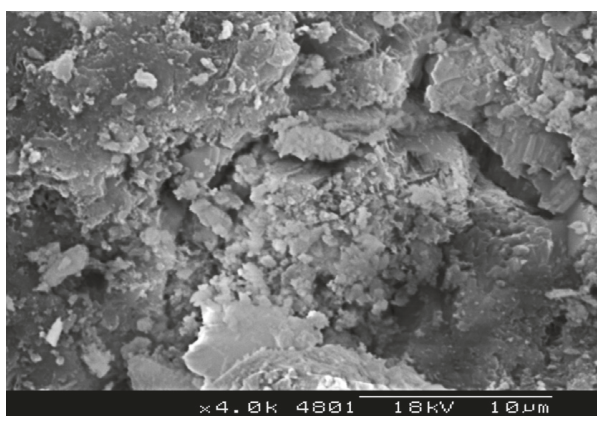

Figure 11: Microstructure of GC5 (too much SF, at 28 days).

tensile, and bending stresses. Therefore, this study examined tensile shear bonding strength and bending tensile bonding strength of the SF-modified UCF.

The results of tensile shear bonding strength and bending tensile bonding strength at 28 days of age are shown in Table 6 and Figure 12. The results showed that the tensile shear bonding strength of the SF-modified UFC paste is 
TABLE 6

\begin{tabular}{lcccccccc}
\hline Number & \multicolumn{3}{c}{ Tensile shear bonding strength } & \multicolumn{3}{c}{ Bending tensile bonding strength } \\
& $\begin{array}{c}\text { Avg } \\
(\mathrm{MPa})\end{array}$ & $\begin{array}{c}\text { Average } \\
\text { cementation ratio }\end{array}$ & $\begin{array}{c}\text { Max } \\
(\mathrm{MPa})\end{array}$ & $\begin{array}{c}\text { Maximum } \\
\text { cementation ratio }\end{array}$ & $\begin{array}{c}\text { Avg } \\
(\mathrm{MPa})\end{array}$ & $\begin{array}{c}\text { Average } \\
\text { cementation ratio }\end{array}$ & $\begin{array}{c}\text { Max } \\
(\mathrm{MPa})\end{array}$ & $\begin{array}{c}\text { Maximum } \\
\text { cementation ratio }\end{array}$ \\
\hline GC0 & 0.0458 & 1.00 & 0.0625 & 1.00 & 3.48 & 1.00 & 3.55 & 1.00 \\
GC1 & 0.1229 & 2.68 & 0.1500 & 2.40 & 3.21 & 1.00 & 3.65 & 1.00 \\
GC2 & 0.2141 & 4.67 & 0.2625 & 4.20 & 3.37 & 0.92 & 3.78 & 1.03 \\
GC3 & 0.3938 & 8.60 & 0.4313 & 6.90 & 3.75 & 0.97 & 4.11 & 1.06 \\
GC4 & 0.3792 & 8.28 & 0.6625 & 10.60 & 3.73 & 1.08 & 4.03 \\
GC5 & 0.3063 & 6.69 & 0.3375 & 5.40 & 3.59 & 1.07 & 3.99 & 1.16 \\
\hline
\end{tabular}

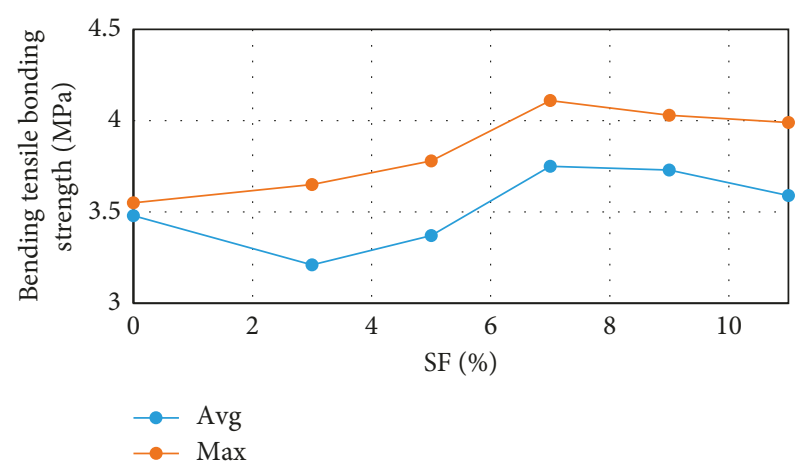

FIgURE 12: Relationship of SF content and bonding strength.

much bigger than that of GC0 regardless of the average or maximum. The average value reached the maximum at the $7 \%$ SF dosage, which is $860 \%$ of the unmodified material. The interface of destruction occurred mostly in the epoxy layer, indicating that the interface bonding strength of this material may play a greater potential in the use of the CCP surface. The bending tensile bonding strength of the UFC specimens improved when the appropriate amount of SF was applied; for example, at $9 \%$ of GC4, the maximum value of $4.03 \mathrm{MPa}$ is reached. Table 6 presents results of interfacial bonding strength of SF-modified UFC.

A large number of researchers have studied the microstructure of the cement-aggregate interface region and found that the cement slurry-aggregate interface area can be divided into three parts, which are the contact layer, enrichment layer, and weak effect layer [22]. The contact layer refers to the area directly in contact with the aggregate interface, with a layer thickness of 2 to $3 \mu \mathrm{m}$. The layer is mainly composed of a CSH gel and fine-grained, densely packed $\mathrm{Ca}(\mathrm{OH})_{2}$ and Aft. 5 to $10 \mu \mathrm{m}$ outside the contact layer is the enrichment layer, where the crystals are coarse, $\mathrm{CH}$ aligned, and less CSH gels. The enrichment layer usually has large gaps and high voidage. Cracks often develop and expand in the enrichment layer. So, it is known as the weak area in the interface area. The successful repair of cracks depends on the microstructure and mechanical properties of the interfacial transition layer, as shown in Figure 13.

SF played a good role in particle filling. A large amount of $\mathrm{Ca}(\mathrm{OH})_{2}$ in the interfacial layer was consumed by secondary pozzolanization to produce lots of $\mathrm{CSH}$ gel and reduce the amount of large crystal lattices of $\mathrm{Ca}(\mathrm{OH})_{2}$ crystals and Aft. At the same time, since the paste modified

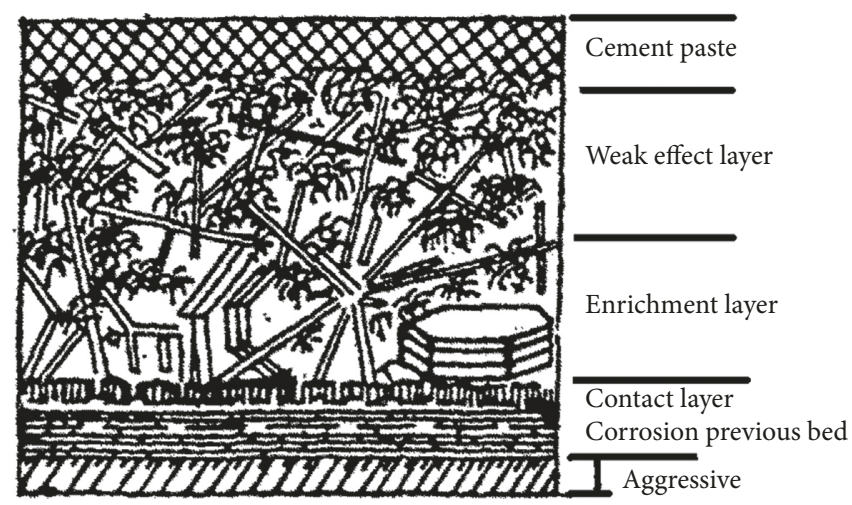

FIGURE 13: Interfacial structure of cement paste and aggregate.

by SF did not bleed water, there is no water film between the colloid and matrix concrete.

Meanwhile, water in the interface area was consumed by the secondary pozzolanic reaction, which brought out good interfacial effect with no water film between the new paste and existing concrete. As seen in the DTA/TG test results shown in Figures 14 and 15, the microstructure of the interface was dense. Thus, interfacial bonding strength was increased by a certain amount of SF. This increase in bonding strength is related to the amount of SF. If the amount is too small, the filling effect and the secondary volcanic ash cannot be fully exerted.

\section{Summary and Conclusions}

Our research focuses on improving the mechanism of mechanical and bonding strength properties of SF-modified UCF. Mechanical performance and bonding strength performance with the variation of SF content have been tested. With XRD, DTA/TG testing, and microscopic morphology observation, the mechanism of the SF-modified UFC is revealed. The main conclusions are as follows:

(1) With SF added, the early hardening of UFC is delayed, which results in reducing the compressive strength of 1-day-old samples. However, the bending strength does not change significantly. At the stable period, the compressive strength increases significantly.

(2) SF reacts with the hydration product of UFC (the secondary pozzolanic reaction). XRD and DTA/TG 


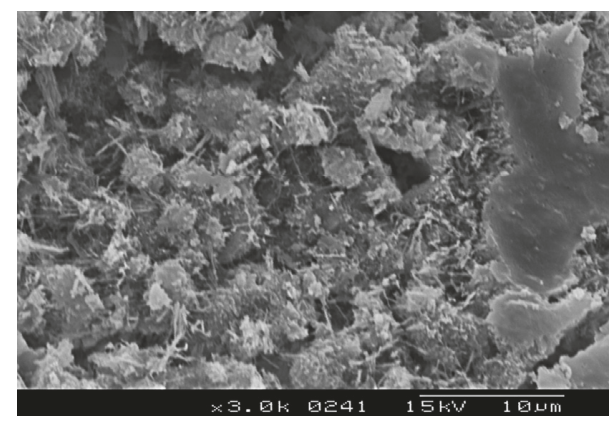

Figure 14: Interfacial microstructure of 28-day GC0 (large crystal lattices of $\mathrm{Ca}(\mathrm{OH})_{2}$ crystals, with loose needles).

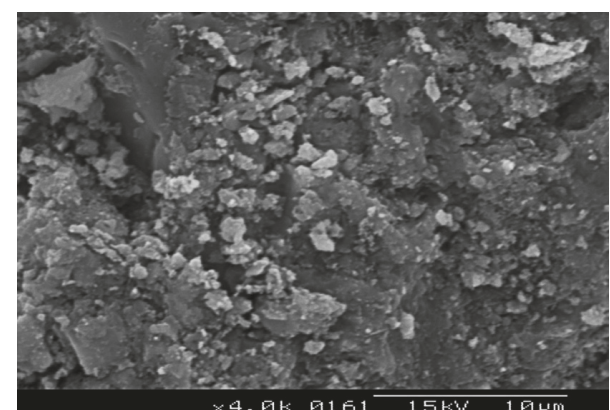

FIgURE 15: Interfacial microstructure of 28-day GC4 (due to the large amount of condensed CSH generated, the interface structure is dense).

tests show that $\mathrm{Ca}(\mathrm{OH})_{2}$ in the hydrated products of GC1 to GC5 is lower than that in the hydrated products of GC0. A reasonable amount of SF leads to good secondary pozzolanic reaction and effective particulate filling results, which improves the cementite microstructure and increases mechanical strength. Our research shows that the specimens of 28 days had good bending strength and compressive strength with 3 to $5 \% \mathrm{SF}$.

(3) With SF added into UFC, tensile shear bonding strength has been greatly improved. However, the bending tensile bonding strength is only slightly improved with a reasonable SF amount. It was observed from the experiments that SF plays a good role in particle filling. A large amount of $\mathrm{Ca}(\mathrm{OH})_{2}$ in the interfacial layer is consumed by secondary pozzolanization to produce lots of $\mathrm{CSH}$ gel. The amount of large crystal lattices of $\mathrm{Ca}(\mathrm{OH})_{2}$ crystals and Aft are reduced. Meanwhile, water in the interface area is consumed by the secondary pozzolanic reaction, which results in a good interfacial effect. With reasonable amount of SF, the interfacial microstructure of the modified material repair becomes dense. Our study shows that 3 9\% SF brought out the best tensile bond strength.

(4) In view of the importance of the mechanical strength and bonding strength of crack repair materials, it is recommended to use $3-5 \% \mathrm{SF}$ as the preferred amount.
Abbreviations
SF: $\quad$ Silica fume
UFC: Ultrafine cement
CCP: Cement concrete pavement
W/C: Water-cement ratio
MPC: Magnesium phosphate cement
XRD: X-ray diffraction
Aft: $\quad$ Ettringite
$\beta$-C2S: $\beta-2 \mathrm{CaO} \cdot \mathrm{SiO} 2$
DTA: Differential thermal analysis
TG: Thermogravimetric analysis
SEM: Scanning electron microscope
CSH: Hydrated calcium silicate
$\mathrm{CH}: \quad \mathrm{Ca}(\mathrm{OH})_{2}$.

\section{Data Availability}

The data used to support the findings of this study are included within the article.

\section{Conflicts of Interest}

The authors declare that they have no conflicts of interest.

\section{Authors' Contributions}

Xiaofei Wang contributed to the study idea and organized the whole paper. Yinchuan Guo provided technical support and funding and helped in performing the experiments. Jiangbei Yao was involved in performing experiments and providing illustrations. Aiqing Shen contributed to solving the problem during the experiments. Xinwei Li and HuaQiao $\mathrm{Pu}$ processed the experimental data.

\section{Acknowledgments}

This work was financially supported by the National Natural Science Foundation of China (51878297), Guangdong Communication Department (2015-02-003 and 2015-02004), and Open Funding Project of National Engineering Laboratory for Surface Transportation Weather Impacts Prevention (NELJA201701). The authors also thank the National Key Laboratory of Concrete of Tongji University for providing technical support for powder X-ray diffraction and thermal analysis in this study.

\section{References}

[1] X. Wang, Research on Crack Growth Mechanism and Crack Mending Material (GGBFS Modified Micro-Fine Cement) of Cement Concrete Pavement, Chang'an University, Xi'an, China, 2005.

[2] X. Deng, Performance Study on the Fly Ash Based Geopolymer Material for Cement Pavement Rapid Repair, China University of Geosciences, Beijing, China, 2017.

[3] Z. Ma, H. Pang, Y. Yang et al., "Review of research progress in chemical grouting materials," Guangzhou Chemistry, vol. 39, no. 1, pp. 9-13, 2014. 
[4] D. Wang and X. Fang, "Research on epoxy resin grouting material for concrete cracks," New Building Materials, vol. 42, no. 7, pp. 69-72, 2015.

[5] M. Duan, "Properties of latex modified cement concrete and its application," Qilu Petrochemical, vol. 1992, no. 1, pp. 6265, 1992.

[6] Q. Li and S. Wu, "Rapid repair of road surface with special hard concrete," Municipal Technology, vol. 1993, no. 4, pp. 9-13, 1993.

[7] M. Xu and P. Xiao, "Application of silica fume concrete in rapid repair of cement concrete pavement," Concrete and Cement Products, vol. 1996, no. 4, pp. 23-25, 1996.

[8] Z. Rui, Z. Lu, and Z. Xu, "Development and application of "NC" polymer concrete quick repair agent," Shanghai Highway, vol. 1998, no. 2, pp. 21-25, 1998.

[9] K. Guan, "Repairing damaged cement concrete pavement with F type repair Material," Heilongjiang Science and Technology Information, vol. 2013, no. 7, p. 166, 2003.

[10] R. H. Abdul Rahim, K. A. Azizli, Z. Man et al., "Effect of solid to liquid ratio on the mechanical and physical properties of fly ash geopolymer without sodium silicate," Applied Mechanics and Materials, vol. 625, pp. 46-49, 2014.

[11] P. Duxson and J. L. Provis, "Designing precursors for geopolymer cements," Journal of the American Ceramic Society, vol. 91, no. 12, pp. 3864-3869, 2010.

[12] H. K. Tchakoute, A. Elimbi, B. B. D. Kenne et al., "Synthesis of geopolymers from volcanic ash via the alkaline fusion method: effect of $\mathrm{Al}_{2} \mathrm{O}_{3} / \mathrm{Na}_{2} \mathrm{O}$ molar ratio of soda-volcanic ash," Ceramics International, vol. 39, no. 1, pp. 269-276, 2013.

[13] W. C. Wang, H. Y. Wang, and M. H. Lo, "The fresh and engineering properties of alkali activated slag as a function of fly ash replacement and alkali concentration," Construction and Building Materials, vol. 84, pp. 224-229, 2015.

[14] K. Vance, A. Dakhane, G. Sant, and N. Neithalath, "Observations on the rheological response of alkali activated fly ash suspensions: the role of activator type and concentration," Rheologica Acta, vol. 53, no. 10-11, pp. 843-855, 2014.

[15] F. N. Okoye, J. Durgaprasad, and N. B. Singh, "Mechanical properties of alkali activated flyash/kaolin based geopolymer concrete," Construction and Building Materials, vol. 98, pp. 685-691, 2015.

[16] M. T. Junaid, O. Kayali, A. Khennane, and J. Black, "A mix design procedure for low calcium alkali activated fly ash-based concretes," Construction and Building Materials, vol. 79, pp. 301-310, 2015.

[17] K. H. Yang, A. R. Cho, and J. K. Song, "Effect of water-binder ratio on the mechanical properties of calcium hydroxidebased alkali-activated slag concrete," Construction and Building Materials, vol. 29, no. 4, pp. 504-511, 2012.

[18] Z. Shu and K. Gong, "Geopolymer," Journal of Materials Science and Engineering, vol. 21, no. 3, pp. 430-436, 2003.

[19] Q. Zhou, B. Jiao, S. Ding et al., "Research on phosphate cement-based ordinary concrete pavement repair agents," New Building Materials, vol. 38, no. 2, pp. 25-28, 2011.

[20] M. Li, X. Zhi, and A. Yao, "Research on slag-based cement concrete pavement repair materials," Material Review, vol. 28, no. 6, pp. 124-127, 2014.

[21] Institute of Road Science, Ministry of Communications, Test Regulations for Cement and Cement Concrete in Highway Engineering, People's Communications Press, Beijing, China, 2005.

[22] X. Wang, A. Shen, and J. Zhu, "Properties of microcrack mending of granulated ground blast furnace slag modified microfine cement," China Journal of Highway and Transport, vol. 19, no. 3, pp. 24-28, 2006.

[23] Zhongjiao Highway Planning and Design Institute Co., Ltd, Highway Cement Concrete Pavement Design Specification: JTG D40-2011, People's Traffic Press, Beijing, China, 2011. 


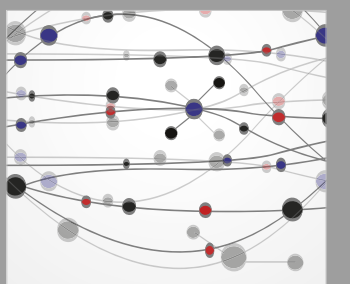

The Scientific World Journal
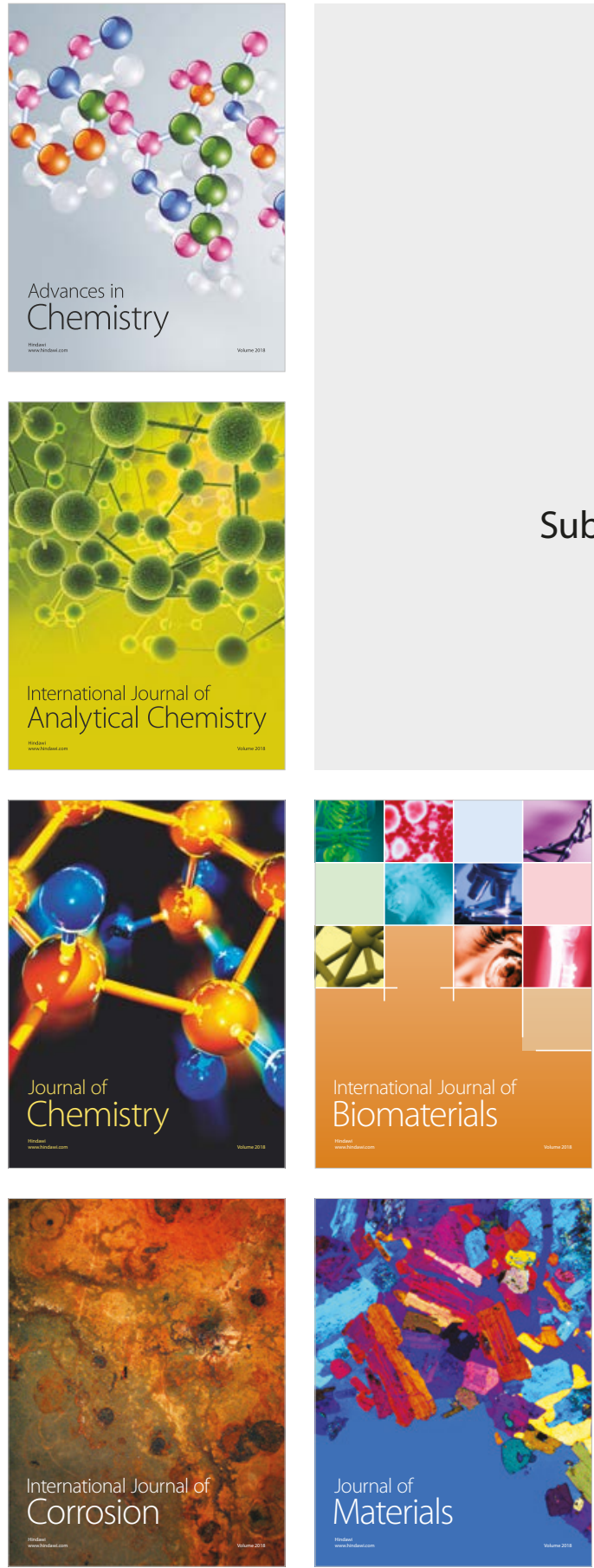

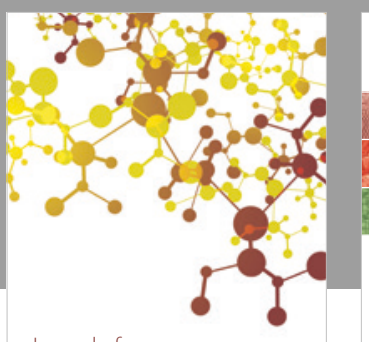

Journal of

Applied Chemistry
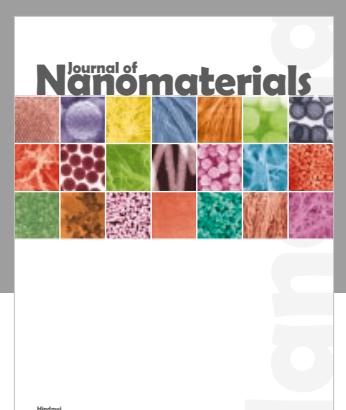

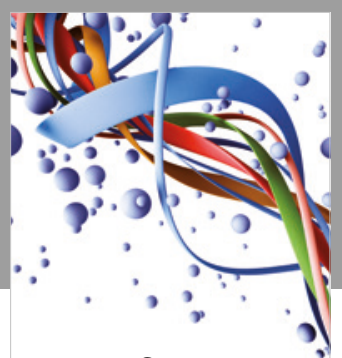

Scientifica

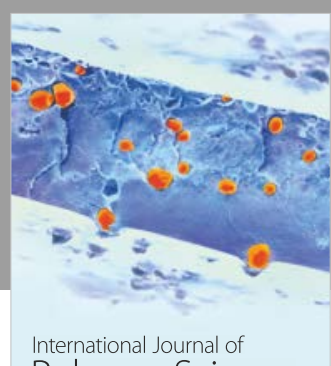

Polymer Science

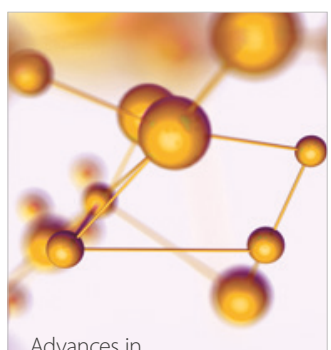

Physical Chemistry
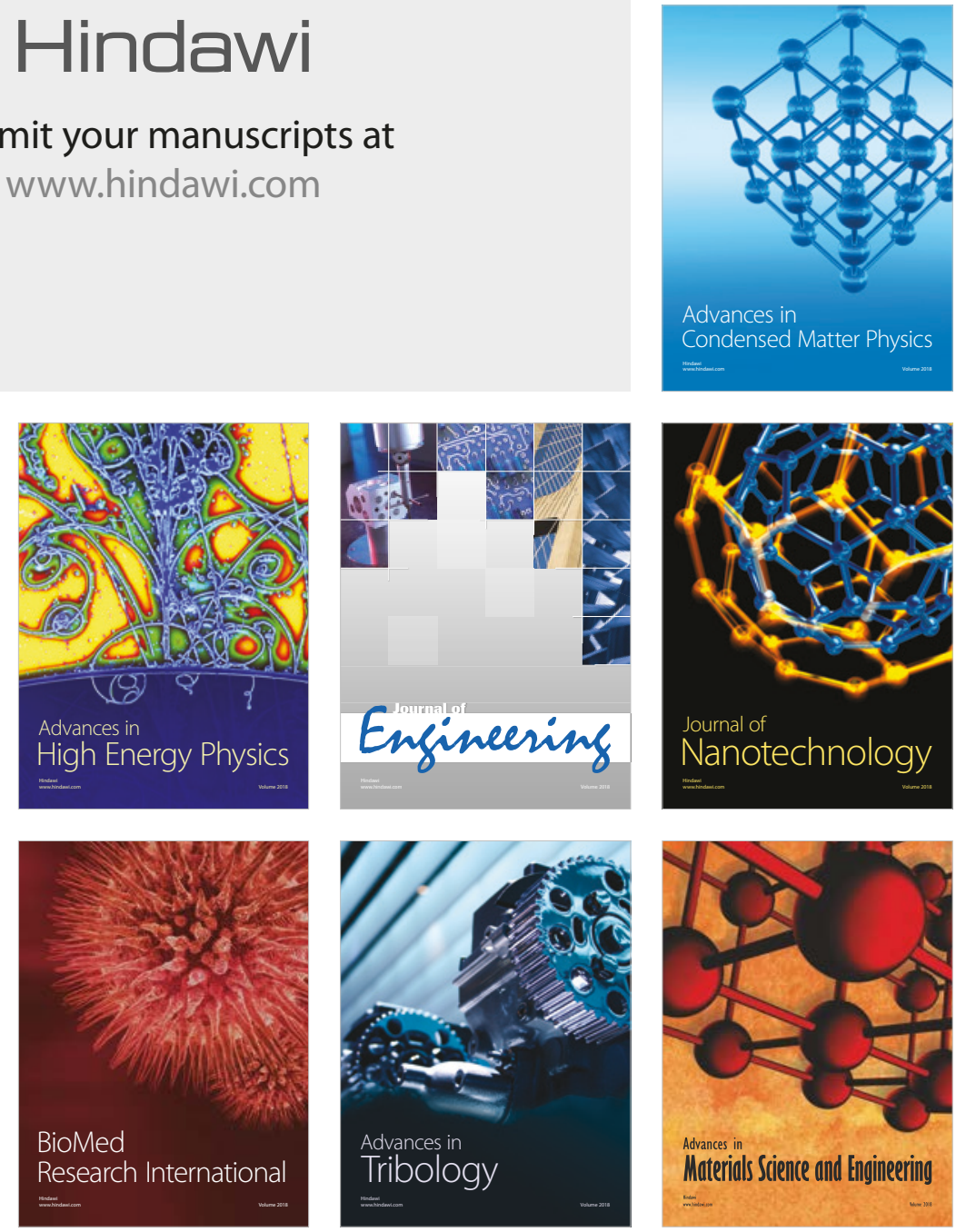